\section{Cannabinoid treatment of opiate addiction}

\author{
Erin McLemon ${ }^{1}{ }^{1}$ and Rose Chesworth $\left(\mathbb{D}{ }^{1, *}\right.$ \\ ${ }^{1}$ School of Medicine, Western Sydney University, Campbelltown NSW 2560, Australia ${ }^{\mathrm{R}}$ \\ *r.chesworth@westernsydney.edu.au
}

\begin{abstract}
Opioid abuse is a growing global problem. Current therapies for opioid abuse target withdrawal symptoms and have several adverse side effects. There are no treatments to address opioid-induced neural adaptations associated with abuse and addiction. Preclinical research demonstrates interactions between the endogenous opioid and cannabinoid systems, suggesting that cannabinoids may be used to treat opioid addiction and dependence. The aim of this review is to assess how cannabinoids affect behavioural and molecular measures of opioid dependence and addiction-like behaviour in animal models. It appears that cannabidiol and cannabinoid receptor $1(\mathrm{CB} 1 \mathrm{R})$ antagonists have potential for treating drug-craving and drug-seeking behaviour, based on evidence from preclinical animal models. Ligands which inhibit the action of cannabinoid degradation enzymes also show promise in reducing opioid withdrawal symptoms and opioid self-administration in rodents. Agonists of CB1R could be useful for treating symptoms of opioid withdrawal; however, the clinical utility of these drugs is limited by side effects, the potential for cannabinoid addiction and an increase in opiate tolerance induced by cannabinoid consumption. The mechanisms by which cannabinoids reduce opioid addiction-relevant behaviours include modulation of cannabinoid, serotonin, and dopamine receptors, as well as signalling cascades involving ERK-CREB-BDNF and peroxisome proliferator-activated receptor- $\alpha$. Identifying the receptors involved and their mechanism of action remains a critical area of future research.
\end{abstract}

Key words: Drug addiction; Mouse models; Behaviour; Opioid; Cannabinoid

\section{Introduction}

There has been a growing trend of opioid dependence and abuse in Australia [1], and globally there were an estimated 26.8 million people with opioid abuse disorder in 2016 [2]. Long-term opioid use is associated with opioid tolerance and toxicity, as well as sleep disorders, endocrinopathies and cognitive impairment [3]. Withdrawal from opioid dependence can induce symptoms such as increased heart rate, blood pressure, perspiration, fluctuating body temperature as well as joint and muscle aches [4]. Longterm management of opioid dependence largely depends on replacement therapy with the opioid agonists such as buprenorphine or methadone [5]. These replacement therapies can reduce withdrawal and relapse [6]. However, treatment with opioid agonists can have similar side effects to long-term opioid use [7, 8], and these agonists do not alter neural adaptations which increase relapse propensity (e.g. altered activity of dopaminergic VTA neurons in response to morphine $[9,10])$. Thus, there is an urgency to uncover other strategies to manage opioid dependence and addiction.

Clinical evidence suggests cannabinoids, which are compounds found in the Cannabis sativa plant that bind to endogenous cannabinoid receptors, may present an effective therapeutic option for managing opioid addiction. Some individuals who use cannabis while undergoing opioid withdrawal perceive an alleviation of some opioid withdrawal symptoms [11], and there is a negative correlation between reported cannabis use and injected opioid drug use (i.e. increased cannabis use corresponds with decreased opioid use) [12]. Supporting this, some American states have reported decreased opioid use after cannabis legalisation [13]. These results are perhaps not surprising, considering well-established interactions between the endogenous opioid and the endogenous cannabinoid (endocannabinoid) systems, with both systems being involved in pain relief, and opioid and cannabinoid receptors are expressed in neural pathways and brain regions associated with addiction [14-17].

In this narrative mini-review we will examine the therapeutic potential of cannabinoids for opioid dependence and addictionlike behaviour, using data from preclinical animal models. We will first outline the endogenous opioid and endocannabinoid systems as well as interactions between them. We will then detail reductions in addiction-like behaviour by cannabinoid compounds in animal models of opioid addiction-relevant behaviour, and in clinical trials, where this data is available. 


\section{The Endogenous Opioid System}

The endogenous opioid system is composed of receptors and peptide chains found in the central, peripheral, and enteric nervous systems. The endogenous opioid peptides are B-endorphin, metand leu-enkephalin, dynorphins, and neo-endorphins [18]. There are also three identified precursors to these peptides: proopiomelanocortin, proenkephalin, and prodynorphin [18]. Opioid receptors, $\mu$ - (MOR), $\delta$ - (DOR) and $\chi^{-}$(KOR) are G-protein coupled receptors that inhibit adenylyl cyclase activity, block calcium channels, and activate potassium channels [19]. Importantly, opioid receptors are highly expressed in brain regions associated with reward (see Table 1 for definitions), including the ventral tegmental area (VTA), nucleus accumbens (NAc), hypothalamus and amygdala [17]. Opioid reward, tolerance and relapse-like behaviour are associated with MOR activation [20-22], while DOR appear involved in the maintenance of opioid reward and dysphoric aspects of opioids, including depression and anxiety [21-23]. KOR modulates drug consumption as well as anxiety and depressive-like behaviours [21, 22]. MOR can mediate glutamatergic activity in the NAc and chronic MOR activation can lead to glutamate dysfunction (e.g. decreased GluR1 surface expression following chronic morphine) [24]. Importantly, glutamate dysfunction is associated with the development of compulsive behaviour for abused drugs and plays a significant role in substance use disorder [25], providing a potential mechanism for how MOR activation can result in addiction-relevant behaviour.

\section{The Endocannabinoid System}

The endocannabinoid system is composed of endogenous receptors (e.g. cannabinoid receptor 1 and 2, CB1R and CB2R respectively), ligands [e.g. 2-arachidonoylglycerol (2-AG) and $\mathrm{N}$-arachidonoylethanolamine (anandamide)] and enzymes for the synthesis and degradation of cannabinoid compounds [e.g. fatty acid amide hydrolase (FAAH), diacylglycerol lipase alpha (DAGL $\alpha$ ), monoacylglycerol lipase (MAGL), and $\alpha / \beta$-hydrolase domain-containing 6 (ABHD6)] [26, 27]. In the central nervous system, CB1R are predominantly expressed on neuronal terminals, and are more highly expressed than $\mathrm{CB} 2 \mathrm{R}$, which are expressed on dopamine neurons in the VTA [28]. Like opioid receptors, CB1R is a G-protein coupled receptor, and regulates activity of cyclic adenosine monophosphate (CAMP), dopamine, $\gamma$-aminobutyric acid (GABA) and glutamate [29]. CB1R is highly expressed in regions of the brain associated with reward and learning, with high levels of receptor expression in the cortex, striatum, hippocampus, thalamus, hypothalamus, substantia nigra pars reticulata and cerebellum $[30,31]$. The endocannabinoid system alters plasticity in brain areas responsible for emotional responses and memory formation, modulating hippocampal synaptic strength, regulating VTA-NAc pathways and reducing glutamatergic activity in the dorsal and ventral striatum [32]. Considering both the endogenous opioid and endocannabinoid systems are involved in processes associated with addiction, it is necessary to consider how these systems interact.

\section{Endogenous opioid and endocannabinoid inter- actions}

The endogenous opioid and endocannabinoid systems interact anatomically and functionally. Anatomically, there is an overlap in the distribution of MOR and CB1R in the limbic system [17, 19]. Agonists for both receptors produce antinociception, sedation, hypotension, motor depression and mediate signalling pathways associated with drug tolerance, dependence and substance use disorder [14].
Table 1. Technical Terms

\begin{tabular}{|c|c|}
\hline Term & Definition \\
\hline Acquisition & $\begin{array}{l}\text { Initial learning of drug reward associations } \\
\text { or drug reinforcement behaviours. }\end{array}$ \\
\hline Aversion & $\begin{array}{l}\text { Dislike of a drug/drug cues/drug context; } \\
\text { evidenced by staying away from a } \\
\text { drug-associated context or cessation of } \\
\text { drug self-administration. }\end{array}$ \\
\hline Cannabinoids & $\begin{array}{l}\text { Compounds from the Cannabis Sativa } \\
\text { plant which bind to endogenous } \\
\text { cannabinoid receptors. }\end{array}$ \\
\hline Extinction & $\begin{array}{l}\text { Cessation of drug-taking behaviours } \\
\text { and/or decreased strength of } \\
\text { drug-cue/context associations. }\end{array}$ \\
\hline Opioids & $\begin{array}{l}\text { Substances that act on opioid receptors, } \\
\text { and can produce effects such as pain relief } \\
\text { and reward. }\end{array}$ \\
\hline Psychoactive & $\begin{array}{l}\text { A chemical substance that changes } \\
\text { nervous system function and results in } \\
\text { alterations in perception, mood, } \\
\text { consciousness, cognition, or behaviour. }\end{array}$ \\
\hline Reward & $\begin{array}{l}\text { An experience which is subjectively } \\
\text { pleasurable. In preclinical models, reward } \\
\text { refers to associations between an } \\
\text { unconditioned stimulus, for example a } \\
\text { drug, and a discrete cue/context. } \\
\text { Rewarding stimuli can elicit approach } \\
\text { behaviour in an attempt to experience the } \\
\text { rewarding stimulus again. }\end{array}$ \\
\hline Reinforcement & $\begin{array}{l}\text { Strengthening the stimulus-response } \\
\text { relationship between a behaviour and drug. }\end{array}$ \\
\hline Reinstatement & $\begin{array}{l}\text { Drug cues, stress or a low dose drug prime } \\
\text { can cause the return of drug-seeking } \\
\text { behaviours or approach of a } \\
\text { drug-associated environment. }\end{array}$ \\
\hline Self-administration & $\begin{array}{l}\text { Behavioural paradigm in rodents, where } \\
\text { animals learn to infuse or consume drugs } \\
\text { of abuse via an operant response e.g. nose } \\
\text { poke, lever press. }\end{array}$ \\
\hline Withdrawal & $\begin{array}{l}\text { Physiological effects following cessation of } \\
\text { drug use. }\end{array}$ \\
\hline
\end{tabular}

Cannabinoid treatment can influence endogenous opioid signalling and function. Acute exposure to CB1R agonists, $\Delta^{9}$ tetrahydrocannabinol (THC) and CP55,940, increases the activity of endogenous opioid peptides $[33,34]$, while chronic exposure to the CB1R agonists THC, R-methanandamide (AM356) and CP55,940 increases levels of endogenous opioid precursors (e.g. dynorphin B) [33]. Chronic exposure to CB1R agonists can cause cellular tolerance to opioids and desensitisation of MOR [35]. CB1R agonists can increase the antinociceptive effects of opioids, by several mechanisms including increasing the release of the endogenous opioid dynorphin A [36]. Cannabinoids such as THC and cannabidiol (CBD) can allosterically modulate MOR and DOR, altering the ability of opioid ligands to bind to and remain at the binding site [37]. FAAH inhibitors, in conjunction with anandamide, produce antinociceptive effects via CB1R and KOR [38]. This data indicates several cannabinoid agonists and enzyme inhibitors can modulate opioid receptor signalling and binding.

These interactions are reciprocal, with opioids affecting the function of the endocannabinoid system. Activation of opioid receptors can cause tolerance and downregulation of cannabinoid receptors [16]. Acute morphine administration reduces the expression of CB1R in the dorsal caudate putamen, NAc and septum; however, chronic morphine increases CB1R expression in the caudate putamen, cortex and midbrain $[39,40]$. In addition, MOR and KOR can mediate rewarding properties of cannabinoids, with MOR 


\section{B) SPONTANEOUS WITHDRAWAL}

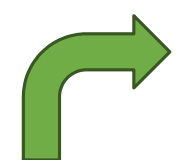

A) DRUG ADMINISTRATION
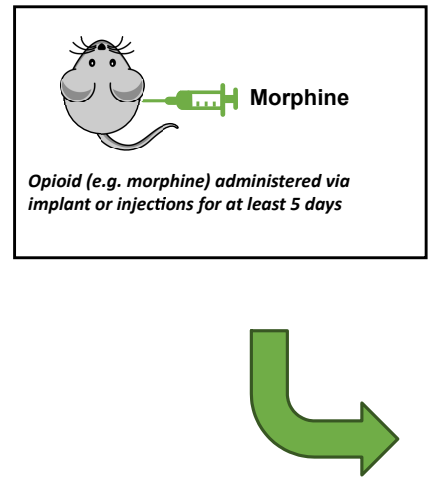
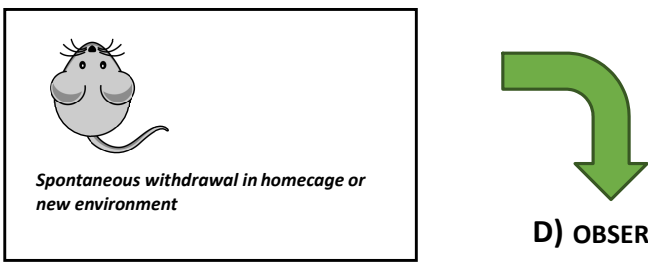

D) OBSERVATION

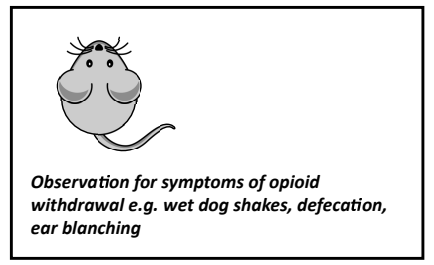

C) ANTAGONIST-INDUCED WITHDRAWAL

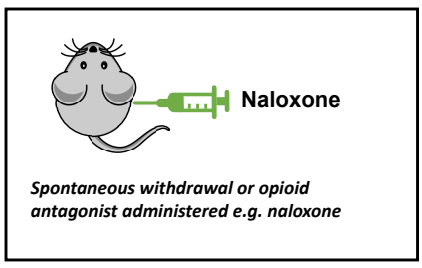

Figure 1. Components of the addiction cycle as modelled in rodents using opiate withdrawal. The addiction cycle, described by Piazza and Deroche-Gamonet [139], includes A) sustained drug use (at least 5 days via mini-pump or repeated injections), B) spontaneous withdrawal in home cage or novel environment or C) opiate-induced withdrawal. Withdrawal symptoms are assessed by a trained observer in D).

being necessary for THC reward in conditioned place preference (CPP) [41]. Naloxone, a MOR antagonist, can induce cannabinoid withdrawal symptoms and inhibit the self-administration of CB1R agonists WIN55,212-2 and HU-210 in rats [39], suggesting naloxone can partially substitute for CB1R antagonists. MOR and DOR double knock out mice display decreased THC-induced hypothermia, slower development of tolerance and reduced expression of withdrawal to THC [42], indicating MOR and DOR act together to modulate addiction-relevant behaviour for THC. These studies suggest the endogenous opioid and endocannabinoid systems interact to regulate addiction-relevant behavioural and neural processes.

\section{Effects of cannabinoids on opioid withdrawal, dependence and addiction-like behaviour: $\Delta^{9}$ - tetrahydrocannabinol (THC)}

THC is the major psychoactive cannabinoid found in cannabis sativa and primarily mediates its psychoactive effects through CB1R, of which it is a partial agonist [43]. THC also allosterically modulates MOR [37].

Initial investigations into THC as a treatment for opioid dependence focused on its effects on opioid withdrawal (see Figure 1 for brief methods). THC attenuates naloxone-induced withdrawal symptoms in rats [44-46], without inducing morphine withdrawal itself [44], initially suggesting THC could be useful in preventing morphine withdrawal. Overall, THC reduces the intensity of some morphine withdrawal symptoms, including defecation and diarrhoea but not wet dog shakes and ear blanching [44]. THC treatment also increases the dose of naloxone required to induce morphine withdrawal $[45,47]$, suggesting protection from naloxone-precipitated morphine withdrawal by THC and potential activation of MOR by THC. Similar effects on naloxone-precipitated withdrawal are reported for THC analogues, such as $\Delta^{8}$-tetrahydrocannabinol and 11-hydroxy- $\Delta^{8}$ tetrahydrocannabinol [47-49]. These early studies suggested that THC or THC-induced mechanisms could be relevant in treating opioid withdrawal. Early clinical studies appeared to support this hypothesis. A reduction in opioid withdrawal by the synthetic THC stereoisomer dronabinol was reported in humans $[50,51]$. An initial study showed that $30 \mathrm{mg}$ of dronabinol reduced opioid withdrawal symptoms during an early detoxification period before administration of the extended release MOR antagonist naltrexone [50]. There were no differences between the dronabinol and the control group in retention and medication compliance following initial detoxification [50]. Interestingly, patients in this study who smoked marijuana were more likely to remain in treatment and had less difficulty with insomnia and anxiety, irrespective of dronabinol treatment, suggesting therapeutic utility of marijuana and possibly THC in withdrawal symptom management [50]. Similarly, 20 and $30 \mathrm{mg}$ dronabinol can supress opiate withdrawal symptoms in opioid-dependent patients [51]. Despite promising effects of dronabinol in reducing initial opioid withdrawal, doses of dronabinol over $20 \mathrm{mg}$ during opioid withdrawal can increase the risk of tachycardia, sedation and perceived drug high, raising safety concerns about its use and limiting the potential of dronabinol in clinical settings $[51,52]$. These later clinical studies indicate that despite initial promise, THC does not appear a viable treatment for opioid withdrawal.

However, THC could be used to treat other aspects of opioid addiction. Some studies indicate that acute THC can reduce the rewarding effects of opiate (i.e. eliciting approach behaviour, such as in conditioned place preference [53]; see Figure 2 for brief methods) and reinforcing effects of opiates (i.e. strengthening the stimulus-response relationship between a behaviour and drug infusion, such as in self-administration [53], see Figure 3 for brief methods). In a self-administration paradigm in rhesus monkeys, acute and repeated THC dose dependently reduces heroin selfadministration, suggesting a reduction in heroin reinforcement when THC is present $[54,55]$. Similarly, in Sprague-Dawley rats, THC also reduces fixed ratio operant responding for heroin [56], 


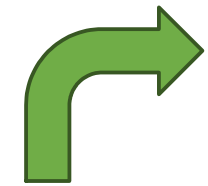

D) REINSTATEMENT: preference for drug environment

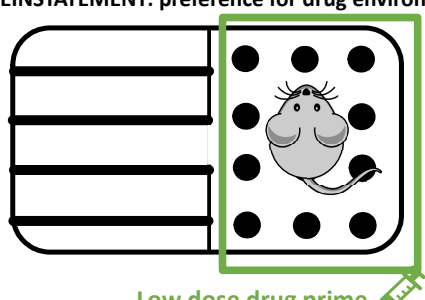

Low dose drug prime

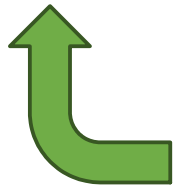

A) ACQUISITION: drug is available

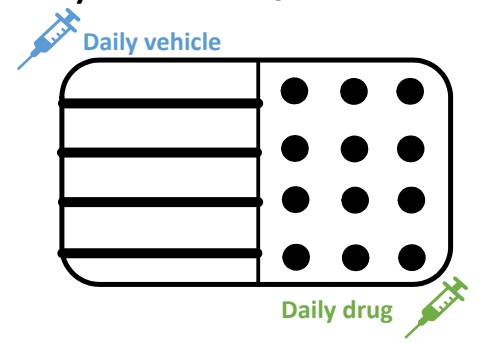

C) Abstinence in home cage: drug is not available

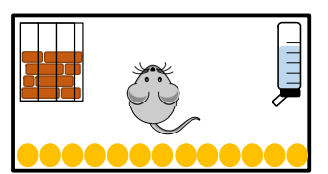

EXTINCTION: drug is not available

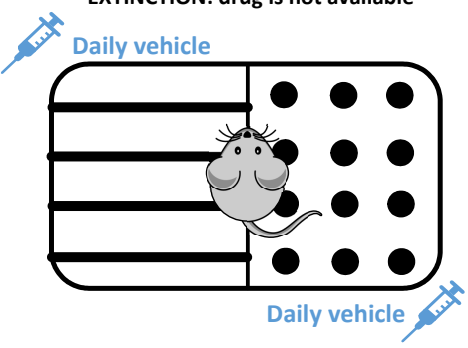

B) TEST: preference for drug environment

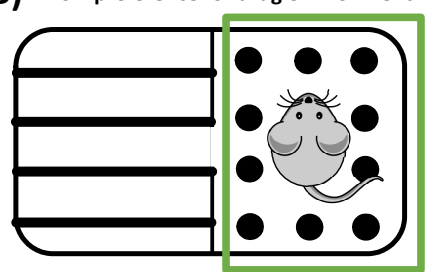

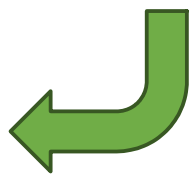

Figure 2. Components of the addiction cycle as modelled in rodents using conditioned place preference. The addiction cycle, described by Piazza and Deroche-Gamonet [139], includes A,B) recreational / sporadic drug use, C) extinction / abstinence, and D) relapse. These are modelled in rodents via A) drug-environment Conditioning sessions (recreational / sporadic drug use) B) the establishment of drug-environment preference at Test (recreational / sporadic drug use), C) extinction training or home cage abstinence (extinction / abstinence), and D) drug-primed reinstatement (relapse).

suggesting THC can reduce the reinforcing properties of heroin. However, some studies show opposite effects, indicating THC can increase opiate reward and reinforcement. One study demonstrated that low dose THC can increase motivation for heroin on a progressive ratio schedule in Sprague-Dawley rats, but this effect was only evident when response requirements for heroin were low [56], and the THC dose used in this study was lower than that used in fixed ratio studies. Recently, it was shown that ventral hippocampal THC infusions can increase reward for subthreshold morphine in a place preference paradigm in rats [57]. In this experiment, THC increased frequency and bursting rates of VTA dopaminergic neurons, which may account for the increase in the rewarding properties of THC combined with subthreshold morphine [57]. Earlier research did not identify a neural locus of effect when demonstrating that systemic THC can reduce opiate reward and reinforcement (e.g. [54-56]), and it is possible that the site where THC acts in the brain can modulate whether THC enhances or impedes opiate reward. Overall, systemic THC appears to reduce opiate reinforcement, but there may also be dose- and locationdependent effects of THC on opiate-induced reinforcement.

Despite this, THC does not appear to strongly modulate opiate extinction or reinstatement. Low dose THC does not reinstate heroin-seeking behaviour in rats, in the absence of heroin cues, a heroin prime or a stressor [58]. Similarly, in rhesus monkeys, daily THC does not affect extinction of heroin-seeking or resumption of heroin self-administration after extinction [55]. While there is limited preclinical research on this topic, the data available suggests THC affects opiate reward and reinforcement, but not extinction and reinstatement processes.

Adolescent cannabis use is associated with increased susceptibility for developing later substance use disorder [59], and understanding the persistent effects of THC exposure in adolescence may help explain the involvement of prior cannabinoid use on opioid addiction. Despite adult THC treatment mostly reducing heroin use in rodents, adolescent THC exposure appears to increase susceptibility to addiction-like behaviour and brain changes in adulthood. Chronic adolescent THC treatment increases heroin self-administration in adult rats at moderate heroin doses (i.e. $50-85 \mu \mathrm{g} / \mathrm{kg} /$ infusion $[60,61]$ ), but not low heroin doses (i.e. $20 \mu \mathrm{g} / \mathrm{kg} /$ infusion [62]). Adolescent THC increases preproenkephalin mRNA expression and MOR guanosine triphosphate-coupling in the NAc shell in adulthood [60], and MOR function in the NAc shell is correlated with heroin intake [60]. Adolescent THC exposure also increases stress-induced reinstatement for heroin in adult rats [62], suggesting adolescent THC can increase opiate relapse propensity. Strain dependent effects of adolescent THC have also been reported: In Lewis rats, a strain that more readily acquires psychostimulant and opiate selfadministration than other outbred rat strains such as Fisher 344 rats [63], adolescent THC has no effect on acquisition of heroin $\mathrm{CPP}$, but potentiates heroin-primed reinstatement of CPP, and increases self-administration and motivation for heroin $[64,65]$. 
However, in Fischer 344 rats, a strain that displays resistance to opiate self-administration [63] , THC exposure increases heroin CPP and increases cue-induced reinstatement of heroin-seeking, but has no effect on self-administration and motivation for heroin $[64,65]$. This suggests that THC can increase susceptibility to opiate abuse-like behaviours, irrespective of genetic susceptibility or resistance to opiate self-administration. Together, this data suggests adolescent THC treatment can increase susceptibility to adult heroin addiction-like behaviour.

Despite this, opposing effects have been reported for the highly selective MOR agonist oxycodone, whereby chronic adolescent THC can reduce oxycodone self-administration in adult rats in a dose dependent manner $[66,67]$. These effects are observed only under extended access conditions, and are blocked by administration of the CB1R antagonist SR141716 [66, 67], suggesting the decreased susceptibility to oxycodone by THC is mediated by CB1R. The reasons for different effects of adolescent THC on subsequent heroin and oxycodone administration are yet to be resolved, but may result from methodological differences (e.g. extended access conditions [67]) and pharmacokinetic differences between heroin and oxycodone (e.g. heroin has a higher affinity for the MOR than oxycodone).

In conclusion, while adolescent THC appears to increase subsequent opioid susceptibility, THC treatment in adulthood can reduce the rewarding and reinforcing effects of opioids. This effect may be mediated through THC-induced activation of CB1R [67]. While the side effect profile and abuse potential of THC can limit its application in the clinic, understanding THC's mechanisms of action in reducing opioid reward could lead to the development of novel compounds targeting these mechanisms. Further research into the receptors and/or proteins THC acts on alter opiate addiction-relevant behaviours is strongly warranted.

\section{CB1R agonists}

Considering the reduction in opioid withdrawal by THC appears mediated by $\mathrm{CB} 1 \mathrm{R}$, other $\mathrm{CB} 1 \mathrm{R}$ agonists have been investigated for their potential to limit opioid withdrawal and addiction-like behaviours. Administration of $\mathrm{CB} 1 \mathrm{R}$ agonists can reduce opioid withdrawal symptoms. The CB1R agonist WIN 55,212-2 decreases the intensity of morphine withdrawal-induced contractions in guinea-pig ileum cells [68]. Smooth muscle activity, as seen in the ileum, is associated with opioid-induced constipation and withdrawal-associated diarrhea [4]. Administration of the endogenous CB1R agonist 2-AG or the $\mathrm{CB} 1 \mathrm{R}$ agonist $\mathrm{HU}-210$ reduces naloxone-precipitated morphine withdrawal in morphine dependent mice [49]. This is consistent with studies showing THC, a partial CB1R agonist, attenuates opioid withdrawal symptoms [4446] and further supports the theory that opioid withdrawal may be mediated by CB1R.

While CB1R agonists appear to reduce opiate withdrawal symptoms, several studies indicate they can also increase the abuse potential of opiates. Systemic [69] and intra-basolateral amygdala [70] WIN 55,212-2 administration increases morphine reward in mice and rats, and this effect is dependent on $\mathrm{CB} 1 \mathrm{R}$, as it is blocked by co-administration of CB1R antagonist SR141716A [69]. In rats, chronic pretreatment with the CB1R agonist CP 55,940 increases subsequent morphine self-administration and locomotor sensitization [71], while acute WIN 55,212-2 increases heroin self-administration in Sprague-Dawley rats [72]. In monkeys selfadministering heroin, CP 55,940 and WIN 55,212-2 reduce heroin self-administration [73]. However, the doses used in this study also decrease responding for a food reinforcer [73], which may suggest CP 55,940 and WIN 55,212-2 reduce locomotor activity in general, and confound the interpretation that these agonists limit heroin self-administration. These results indicate that $\mathrm{CB} 1 \mathrm{R}$ agonists often increase opioid reward.
It seems enhancing effects of CB1R agonists on opiate reward and reinforcement can be dose-dependent. Co-administration of maximally reinforcing doses of CP 55,940 and heroin decreases lever responding for the combination of both drugs, suggesting CP55,940 can substitute for heroin [74]. Similarly, in a place preference paradigm, CP 55,940 treatment during acquisition of heroin CPP does not enhance the rewarding effects of heroin, yet the doses of CP 55,940 and heroin in this study already were rewarding in CPP, suggesting cannabinoid agonists can enhance opioid reward when subthreshold doses are used [75]. Indeed, this interpretation was recently confirmed - WIN 55,212-2 combined with subthreshold morphine dose-dependently causes a conditioned place aversion (CPA), while supra-threshold doses of morphine combined with WIN 55,212-2 shift morphine CPP to a CPA [76]. Together, these studies suggest that CB1R agonists mostly increase opioid sensitivity and reward, limiting their suitability for opioid addiction treatment. However, there are indications that this increase in opioid reward is only evident in rodents (e.g. [73]), and further research on the interactions between CB1R and opioid reward in primates is warranted.

CB1R agonists can alter the reinstatement of opiate seeking, but whether CB1R agonists facilitate or inhibit reinstatement can depend on the brain region targeted. Systemic administration of HU-210, as well as CP 55,940 and WIN 55,212-2 reinstates drugprimed heroin-seeking in a self-administration paradigm in rats $[58,77]$. However, when WIN 55,212-2 is administered directly into the NAc, it reduces drug-primed reinstatement of morphine CPP in rats [78], and this is associated with elevated NAc and VTA c-fos activation [79]. Discrepancies between systemic and intraNAc CB1R agonist administration may arise due to the role of the NAc in reinstatement. WIN 55,212-2 prior to reinstatement inhibits glutamate inputs to the NAc [80], and glutamatergic activity in the NAc modulates opiate reinstatement [81, 82];[83]. It is possible that while CB1R activation in the NAc alone can reduce drugprimed reinstatement, systemic $\mathrm{CB} 1 \mathrm{R}$ agonist administration may also affect other structures critical for reinstatement, for example $\mathrm{CB1}$ R on cortical glutamatergic afferents regulates dopamine release in the NAc and could increase reinstatement propensity [83]. Despite effects of WIN on reinstatement, intra-NAc WIN given during extinction does not affect extinction or reinstatement of morphine CPP [78], despite WIN increasing NAc neuronal activity when administered during extinction [80], and reducing the pCREB/CREB ratio in the NAc [79]. Thus, while CB1R agonists can modulate relapse-like behaviour for opiates, further research is required to clarify effects of CB1R agonists on extinction of opiates.

\section{Cannabidiol (CBD)}

CBD is a non-intoxicating cannabis constituent with several pharmacological mechanisms, including being a weak negative allosteric modulator of $\mathrm{CB} 1 \mathrm{R}$, a serotoninergic 5-HT1A receptor agonist, and a vanilloid TrpV1 agonist [84-88]. CBD can also allosterically modulate opioid receptors and accelerate MOR agonist dissociation from the binding site, thus reducing MOR activity [37]. CBD is associated with increased endocannabinoid activity by inhibition of FAAH and subsequent increased levels of anandamide by a reduction in the hydrolysis rate [89]. Preclinical research indicates a limited role for CBD in reducing opioid withdrawal symptoms. CBD can reduce naloxone-induced withdrawal symptoms [45], but is less effective than other cannabinoids in this effect, for example THC. THC produces a 3- to 6-fold increase in the effective dose of naloxone for precipitating withdrawal, whereas CBD only produces a 2-fold increase in the effective dose of naloxone [45]. CBD also has a limited effect on the expression of opiate withdrawal, modestly decreasing jumping behaviour, but no other behaviours, compared to vehicle controls [45]. While CBD combined with THC increases THC's attenuation of morphine withdrawal, 
A) SELF-ADMINISTRATION: drug is available
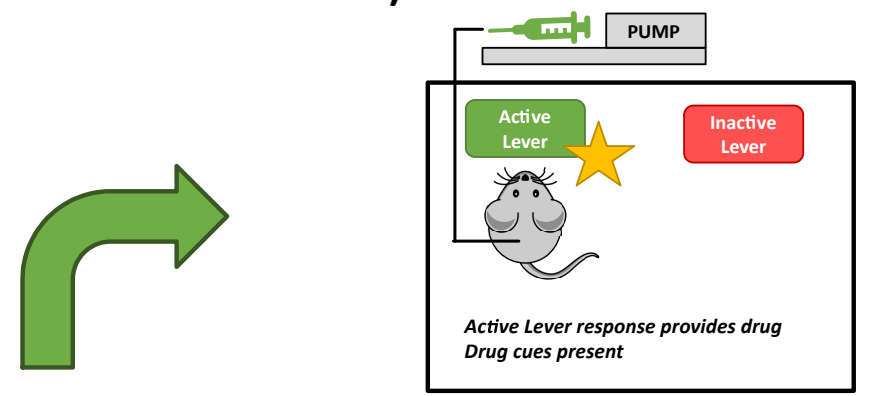

D) REINSTATEMENT: drug is not available

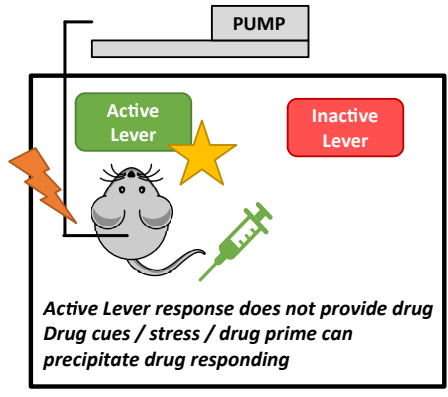

C) ABSTINENCE IN HOME CAGE: drug is not available

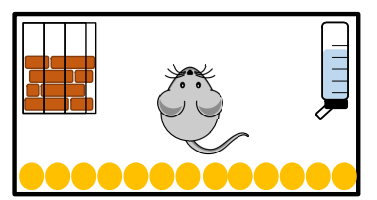

EXTINCTION: drug is not available

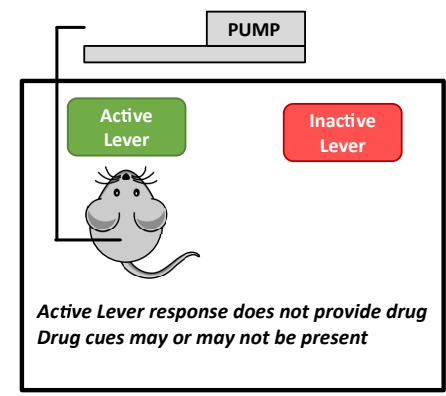

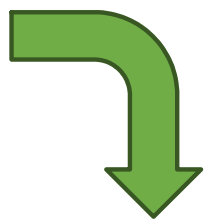

B) ESCALATION: drug is available
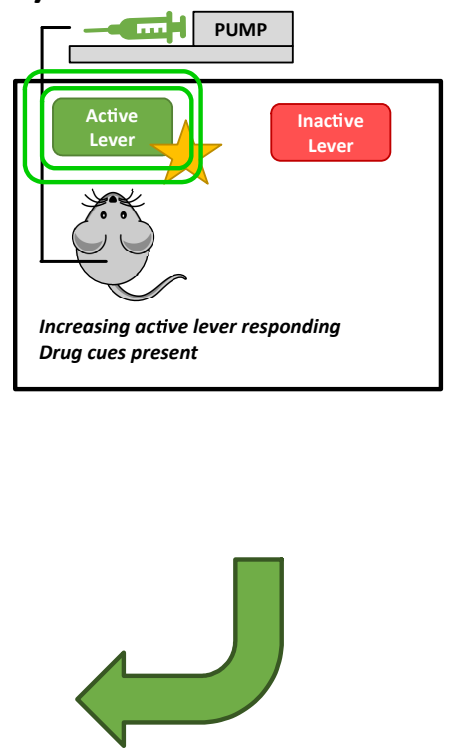

Figure 3. Components of the addiction cycle as modelled in rodents using intravenous self-administration. The addiction cycle, described by Piazza and Deroche-Gamonet [139], includes A) recreational/sporadic drug use, B) escalation of use, C) extinction / abstinence, and D) relapse. These are modelled in rodents via A) self-administration, B) progressive ratio responding, C) extinction training or home cage abstinence, and D) reinstatement (stress / drug-primed / cue-induced).

this combination also increases THC-induced rotational behaviour in rats, potentially limiting the use of THC-CBD combinations for morphine withdrawal [90]. Thus, CBD does not appear to show potential as a treatment for opioid withdrawal.

However, there is some evidence suggesting $\mathrm{CBD}$ attenuates opiate reward. Co-administration of CBD with morphine dosedependently increases the intracranial self-stimulation (ICSS) threshold in the medial forebrain bundle in rats, indicating a reduction in brain reward threshold [91]. CBD's reduction in morphine-induced ICSS was reversed by pretreatment with the serotonergic ( $5-\mathrm{HT}) 1 \mathrm{~A}$ receptor antagonist and potent dopamine D4 receptor (D4R) agonist, WAY-100635, indicating CBD mediates morphine reward via stimulation of 5-HT1A or inhibition of D4R [91]. CBD alone also dose-dependently reduces brain reward thresholds [91]. While infusions of CBD alone into the ventral hippocampus do not affect subthreshold morphine CPP, infusions of CBD in the ventral hippocampus reverse THC's enhancement of subthreshold morphine reward, and these effects are mediated by modulation of extracellular signal-regulated kinase (ERK) phosphorylation [57]. This suggests CBD may reduce THC's enhancement of morphine reward via ERK signalling in the ventral hippocampus [57]. These results indicate that CBD can reduce the rewarding effects of opioids, and these effects can be mediated by 5-HT1A and/or D4 receptors.

CBD may also reduce addiction-relevant behaviour via persistent effects on opiate memory. While CBD does not reduce heroin self-administration or extinction of heroin self-administration in rats, it can reduce cue-induced heroin reinstatement [92]. Effects of $\mathrm{CBD}$ on cue-induced reinstatement are persistent, lasting for 2 weeks after CBD treatment, suggesting long-lasting effects of CBD on opiate-associated cue memory [92]. Similarly, CBD interrupts reconsolidation of morphine CPP memory for up to 14 days after CBD treatment in a rat model, and this does not return upon drug- or stress-primed reinstatement following extinction, again indicating that CBD can impair drug-memory [93]. CBD prior to memory reactivation also suppresses naltrexone-precipitated 
place aversion in the CPP context [93], demonstrating that CBD can limit recall of a drug-associated environment. CBD treatment normalises heroin-induced upregulation of CB1R RNA and protein levels in the NAc core and shell, and downregulates GluR1 protein in the NAc core and shell [92] , suggesting that CBD may ameliorate drug-induced neural adaptations. Together, this suggests CBD can impair opiate-based memory in rodents, potentially by interrupting reconsolidation, and this can occur via modulation of GluR1 and CB1R in the NAc. Recent clinical trials also suggest CBD can reduce opiate craving and the willingness to use opioids. In humans, CBD reduces heroin cue-induced craving and anxiety in heroin abstinent individuals [94]. This effect was observed $24 \mathrm{hr}$ after a single CBD treatment, and persisted for one week following 3 days of CBD treatment [94]. CBD also reduced physiological measures of stress, such as heart rate and salivary cortisol levels, compared to placebo-treated controls, suggesting CBD may reduce physiological responses to stress in order to reduce cue-induced craving for heroin [94]. In addition, a prospective cohort study of patients with chronic pain on long-term opioid treatment demonstrated a trend for CBD treatment to increase willingness to cease opioid medication [95]. In this study, 50 of 94 participants reduced their opioid dose over the eight weeks, and patients indicated reluctance to cease opioid use due to perceived risk of refusal to renew future opioid treatment [95], suggesting that patients may have reduced their opiate use further if they were guaranteed future access to opiates if necessary. Together, this suggests CBD may reduce opiate craving and use in humans, but further research is required to confirm these conclusions.

\section{Cannabinoid enzyme inhibitors: FAAH in- hibitors}

FAAH inhibitors limit the degradation of, and thus increase the concentration of the fatty amide family of lipid transmitters, including the most widely studied endocannabinoid, anandamide. It is hypothesised that FAAH inhibitors can increase anandamide availability, which elevates cannabinoid receptor stimulation and thus reduces the rewarding and relapse-inducing effects of abused drugs, including opiates [96].

FAAH inhibitors show potential in reducing opioid withdrawal. FAAH inhibitors, including URB-597 and PF-3845, reduce withdrawal symptoms in morphine-dependent mice and rats [46, 97, 98]. Recently, N-oleoylglycine (OlGly), a fatty acid amide which appears to act as a FAAH inhibitor and a peroxisome proliferator-activated receptor alpha (PPAR $\alpha$ ) agonist, limited naloxone-precipitated morphine withdrawal symptoms in male rats, including abdominal contractions, lying on belly, diarrhoea and mouthing movements [99]. The effects of OlGly on morphine withdrawal were mediated by CB1R and PPAR $\alpha$ [99], indicating that increasing endogenous cannabinoid levels could be a potential treatment option for opioid dependence. Furthermore, monomethylated oleoyl glycine (HU595), which has improved stability compared to oleoyl glycine and inhibits FAAH and activates PPAR $\alpha$ in vitro, reduces somatic and aversive effects of naloxoneprecipitated morphine withdrawal [100], again suggesting potential as a treatment for opioid withdrawal. Effects of HU595 on morphine withdrawal were prevented by both a PPAR $\alpha$ antagonist and a CB1R antagonist [100], indicating HU595 may reduce naloxoneprecipitated morphine withdrawal by increasing activity of PPAR $\alpha$ and CB1R. HU595 also does not produce rewarding or aversive effects on its own and does not modify locomotor activity, supporting its therapeutic utility [100]. Together, these studies demonstrate that FAAH inhibitors may act via increasing CB1R and PPAR $\alpha$ signalling to limit opioid withdrawal behaviours in rodents.

Some, but not all FAAH inhibitors limit morphine withdrawalinduced place aversion. The FAAH inhibitor URB-597 facilitates extinction of naloxone-precipitated morphine withdrawal- induced conditioned aversion [101], but does not limit morphineinduced reinstatement of CPA [102]. This suggests URB-597 can facilitate extinction memory processes, which can be relevant to reducing morphine use. Similarly, OlGly has been shown to also block the aversive effects of morphine withdrawal in a place aversion paradigm [103], suggesting OlGly can reduce morphine withdrawal effects. However, the FAAH inhibitor PF-3845 does not limit morphine withdrawal-induced CPA [46], and URB597 and $\mathrm{PF}-3845$ have no effect on the establishment or reinstatement of CPA [104]. Despite this, a combination of a low-dose MAGL inhibitor JZL184 and high dose FAAH inhibitor PF-3845, as well as a dual FAAH-MAGL inhibitor SA-57, reduces withdrawal symptoms in morphine-dependent mice [105], but does not prevent naloxone-precipitated withdrawal CPA in mice [46]. While some FAAH inhibitors appear effective in reducing morphine withdrawal symptoms, it appears a dose-dependent combination of FAAH and MAGL inhibition may sometimes be required to reduce morphine withdrawal-induced CPA.

There is limited research into the effects of FAAH inhibitors on addiction-like behaviours for opiates. Administration of AM404, which inhibits anandamide reuptake, reduces motivation for heroin in a self-administration paradigm in rats [56]. Subthreshold doses of AM404 combined with the FAAH inhibitor URB-597 also reduce heroin motivation in a self-administration paradigm in rats [56]. While AM404 is self-administered by rhesus monkeys [106], it is not rewarding in a place preference paradigm in rats [107], and does not enhance BSR in rats [108]. Despite promising findings with $\mathrm{AM}_{404}$, administration of the FAAH inhibitor URB597 does not promote extinction of morphine CPP, or limit subsequent drug-primed reinstatement of morphine CPP [101, 102]. Similarly, OlGly does not limit formation of morphine CPP or prevent reinstatement of morphine CPP [103]. This suggests FAAH inhibitors may reduce motivation for, but not extinction or reinstatement of opiates in rodents.

Clinical trials have started to examine if FAAH inhibitors may be relevant for opioid withdrawal symptoms and opioid selfadministration. While a clinical trial for the FAAH inhibitor BIA102474 was discontinued due to severe side effects [109], a comprehensive review of safety information relevant to BIA10-2474 suggested other FAAH inhibitors do not pose similar safety risks [110], and interest in FAAH inhibitors has recently regained traction. Importantly, FAAH inhibitors such as URB-597 have low abuse liability as they do not induce place preference $[111,112]$, they are not spontaneously self-administered by subjects [113], and have a low toxicity profile [112]. This suggests FAAH inhibitors may have clinical utility in the management of opioid-abuse.

\section{Cannabinoid enzyme inhibitors: MAGL in- hibitors}

Limited research suggests MAGL inhibitors can limit opioid withdrawal and addiction-like behaviours. MAGL inhibitors limit the hydrolysis of 2-AG, increasing endocannabinoid tone. The selective MAGL inhibitor JZL184, which increases levels of 2-AG but not anandamide, blocks naloxone-precipitated and also spontaneous opioid withdrawal symptoms in opioid-dependent mice [46, 97]. Despite this, JZL184 does not prevent naloxone-precipitated CPA in mice [46], suggesting JZL184 can limit withdrawal symptoms but not withdrawal-environment associations. A different MAGL inhibitor, MJN110 prevents acquisition of naloxoneinduced withdrawal CPA in rats, when administered systemically or by direct infusion to the basolateral amygdala or the interoceptive insular cortex; the latter region is activated during opioid withdrawal [114]. The dual FAAH-MAGL inhibitor SA-57 reduces heroin self-administration and heroin-seeking in mice [115], suggesting a combined FAAH-MAGL inhibitor may limit relapse-like behaviour. Together, this suggests MAGL inhibition can limit opi- 
oid withdrawal, as well as heroin self-administration and heroinseeking. New therapeutic options may include combinations of MAGL and FAAH inhibition [115], particularly for the inhibition of opioid withdrawal.

\section{CB1R antagonists}

CB1R antagonists show potential for the treatment of opioid withdrawal. While acute administration of the CB1R antagonist SR141716A induces morphine withdrawal in morphinedependent rats [116], chronic administration of the CB1R antagonist SR141716A reduces spontaneous morphine withdrawal symptoms, including wet shakes and jumping [117]. Despite this, there is no effect of acute SR141716A on naloxone-induced withdrawal [117]. CB1R knockout mice also express reduced withdrawal symptoms after naloxone administration [118], suggesting chronic, but not acute CB1R antagonism may be relevant for reducing morphine withdrawal.

Acute administration of the CB1R antagonists AM251, AM4113 and AM6527 inhibits morphine withdrawal-induced CPA in rats, but has no effect on the reinstatement of CPA [104]. Direct infusions of AM251 into the bed nucleus of the stria terminalis and the central amygdala reduces morphine withdrawal-induced CPA, suggesting a key role for these regions in morphine withdrawal CPA [119].

$\mathrm{CB} 1 \mathrm{R}$ antagonists also show therapeutic potential for reducing opiate reward and relapse-like behaviour. Several studies indicate SR141716A significantly reduces opioid reinforcement: self-administration and motivation for heroin is significantly reduced in rats co-treated with SR141716A [39, 74, 77], while selfadministration of morphine is blocked by SR141716A pretreatment in mice [39]. SR141716A pretreatment also inhibits acquisition of morphine CPP in mice [39, 69, 117], suggesting SR141716A can block morphine reward. SR141716A infusions into the NAc of rats during morphine withdrawal reduces preference for a morphineassociated environment [120], suggesting SR141716A can facilitate the loss of morphine-environment associations. SR141716A reduces drug-primed reinstatement of heroin and morphine [69, 77], even after an extended period of abstinence [15], indicating potential for reducing relapse-like behaviour. Effects of CB1R blockade on opiate reinstatement appear mediated by the NAc core and prefrontal cortex, as SR141716A infused into the NAc core and prefrontal cortex, but not the basolateral amygdala, attenuates cue-induced reinstatement of heroin-seeking [121]. However, chronic pretreatment with SR141716A does not reduce subsequent morphine-induced locomotor stimulation [71], and higher doses of SR141716A also induce place aversion in opiatedependent mice and rats [39, 117], suggesting therapeutic effects of SR141716A occur within a specific dose range. Furthermore, while SR141716A does not exhibit rewarding properties in a place preference paradigm [117], it does increase brain stimulation reward thresholds [122] and reduces responding for foodpredictive cues [123], suggesting it may have depressant-like effects or mood altering properties. Recently, due to side effects associated with SR141716A treatment in clinical trials (e.g. anxiety, depression, suicidal thoughts), investigations into other CB1R modulators have been conducted.

Recent investigations into other CB1R antagonists indicate therapeutic potential for opiate addiction-like behaviour. The CB1R antagonist AM251 impairs acquisition of morphine CPP in mice, indicating a reduction in morphine reward [124]. Also, the CB1R neutral antagonist AM/113 dose-dependently inhibits selfadministration of intravenous heroin in rats, with no effect on brain stimulation reward thresholds [122], suggesting AM 4113 can reduce heroin reinforcement. There are mixed reports on whether AM251 can enhance extinction of morphine CPP: one study demonstrated that systemic AM251 did not facilitate extinction of mor- phine CPP in rats [101]. However, intra-NAc AM251 reduces morphine CPP reinstatement following extinction [125], and infusions of AM251 into the dorsal hippocampus, but not the prefrontal cortex, inhibits drug-primed reinstatement of morphine CPP [126]; suggesting AM251 can limit reinstatement of morphine-seeking, even if AM251 does not affect extinction. AM251 treatment prior to reinstatement blocks the morphine-induced upregulation of $\mathrm{CB} 1 \mathrm{R}$ in the NAc and the hippocampus, and reduces activation of the ERK-CREB-BDNF cascade in the NAc and hippocampus [79, 124]. Considering the involvement of ERK, CREB and BDNF in neural plasticity, which is critical for drug-associated learning [127, 128], and how CB1Rs bind to $\mathrm{G}_{i / o} \mathrm{G}$-proteins to activate ERK, it is possible CB1R mediates opiate reinstatement via this cascade.

Interestingly, AM251 can also have synergistic effects with morphine. Subchronic intra-NAc AM251 in conjunction with subthreshold morphine produces morphine place preference [129]. AM251 appears to act at the basolateral amygdala and the prelimbic cortex to mediate these synergistic effects with morphine [76, 130]. Effects of AM251 in the prelimbic cortex are blocked by systemic administration of the broad-spectrum dopamine receptor antagonist $\alpha$-flupenthixol, suggesting that CB1R in the prefrontal cortex can mediate a motivational valence switching mechanism which modulates dopaminergic transmission and alters reward value [130]. Synergistic effects between AM251 and opiates, and the potential limitations this could present for the therapeutic utility of CB1R antagonists, requires further investigation.

\section{CB2R agonists}

Recent research suggests some $\mathrm{CB} 2 \mathrm{R}$ agonists can limit opiate addiction-relevant behaviour. Pretreatment with CB2R agonists e.g. AM1710, AM1241 and LY2828360 reduces naloxoneprecipitated opioid withdrawal in morphine-tolerant mice [131134]. Co-treatment with CB2R agonist JWHo15 or LY2828360 blocks acquisition of morphine CPP [131, 135], without producing reward or aversion when administered alone [131]. JWH015 reduces morphine-induced dopamine release in the NAc shell, which may explain the inhibition of morphine reward by this CB2R agonist [135]. This preliminary research supports future investigations into CB2R agonists for the treatment of opiate withdrawal and reward is warranted, and the mechanisms by which this occurs.

\section{Conclusions}

Here we have summarised the therapeutic potential of cannabinoid-based drugs for managing opioid withdrawal, dependence and addiction-like behaviour. Interactions between the endogenous opioid and endocannabinoid systems present a novel therapeutic target for treating opioid addiction. In particular, CBD, FAAH and MAGL inhibitors, as well as CB1R antagonists show potential for treating opiate withdrawal, reward and relapse-like behaviour. Investigations into the mechanisms by which these ligands reduce opiate reward and opiate-seeking behaviour has been limited, but to date include modulation of 5HT1AR, D4R, GluR1 and CB1R (relevant to CBD), CB1R and PPAR $\alpha$ (relevant to FAAH and MAGL inhibitors), and ERK-CREB-BDNF (relevant to CB1R antagonists). While the literature suggests that $\mathrm{CB1R}$ agonists can reduce opiate withdrawal in rodents, CB1R agonists can also enhance opiate reward and precipitate opiate relapse-like behaviour, making these agonists unsuitable in their current form as therapeutic options for opiate addiction. 


\section{Implications and Future Directions}

Several cannabinoid ligands show therapeutic promise in animal models for reducing opiate abuse liability and addiction-like behaviour. This presents a significant array of compounds with treatment potential, and may start to change the perception of cannabinoids from party drug to potential medicine. However, several ligands have significant side effects which can limit their therapeutic application (e.g. hallucinogenic effects of THC, suicidal ideation and anxiety following SR141716A treatment). Also, cannabis use can exacerbate or increase risk for the development of other mental health conditions (e.g. schizophrenia) [136], and it is possible that other cannabinoid compounds may also have similar effects, potentially restricting the use of some cannabinoids in clinical settings.

Nonetheless, research to investigate the mechanisms of action by which these ligands exert anti-addiction-like effects may provide more refined and targeted compounds for opiate abuse treatment. For example, investigations into the mechanisms by which $\mathrm{CB1R}$ agonists reduce opiate withdrawal may provide new therapeutic opportunities for ligands which can limit withdrawal, without enhancing opiate reward. Indeed, interest in cannabinoid ligands as a potential treatment for opioid abuse is evidenced by the recent proliferation of research into $\mathrm{CB1}$ R antagonists, as well as cannabinoid enzyme inhibitors. Furthermore, combinations of some cannabinoid compounds (e.g. FAAH and MAGL inhibitors) may prove more effective than these compounds individually, again providing a new host of potential treatment options. While investigations into CB1R antagonists other than SR141716A and cannabinoid enzyme inhibitors are fairly recent, and the mechanism of action of these drugs is presently unclear, this is an exciting and novel avenue of research. Finally, the potential of CB2R modulators to reduce opiate abuse liability has received very little attention so far, but considering $\mathrm{CB} 2 \mathrm{R}$ can modulate reward behaviours for other abused drugs (e.g. ethanol and cocaine [137, 138]), investigations into how CB2R modulates opiate addictionrelevant behaviours are also warranted.

\section{Declarations}

\section{Acknowledgements}

We would like to thank Jennifer Collins for proof reading the manuscript.

\section{Funding}

$\mathrm{RC}$ is funded by the Ainsworth Medical Research Innovation Fund and the Rebecca Cooper Medical Research Foundation.

\section{Conflict of Interest Declaration}

$\mathrm{RC}$ is an editor for Neuroanatomy and Behaviour and a member of the committee of management of Episteme Health.

\section{Editorial Notes}

\section{History}

- Received: 2020-09-28

- Revisions Requested: 2020-12-13

- Revised: 2021-04-09

- Accepted: 2021-05-14

- Published: 2021-06-12

\section{Editorial Checks}

- Plagiarism: Plagiarism detection software found no evidence of plagiarism.

- References: Zotero did not identify any references in the RetractionWatch database.

\section{Peer Review}

The review process for this paper was conducted double-blind because one of the authors is a member of the committee of management of the publisher, Episteme Health Inc. During review, neither the authors nor the reviewers were aware of each other's identities.

For the benefit of readers, reviewers are asked to write a public summary of their review to highlight the key strengths and weaknesses of the paper. Signing of reviews is optional.

\section{Reviewer 1 (Anonymous)}

This paper provides a review and synthesis of the available pre-clinical evidence for the role of cannabinoids in opiate dependence-related behaviours. The authors provide a comprehensive overview of research in animal models and make some suggestions for future research and practice.

\section{Reviewer 2 (Anonymous)}

The authors have written a comprehensive review of literature suggesting that cannabinoids have therapeutic potential in treating opiate addiction. The manuscript was carefully revised and significantly improved. The amount of literature reviewed is impressive. Notably, a commendable effort has been made to improve the clarity of writing, for example by paying more attention to the topic and concluding sentences in each paragraph. The new implications section at the end of the manuscript is a welcome addition and nicely contextualises the material covered in the manuscript.

\section{Reviewer 3 - References Review (Anonymous)}

I have checked the references that the authors have changed in the revised manuscript.

\section{References}

1. Blanch B, Pearson SA, Haber PS. An overview of the patterns of prescription opioid use, costs and related harms in Australia. Br J Clin Pharmacol. 2014;78(5):1159-66. doi: 10.1111/bcp.12446

2. Strang J, Volkow ND, Degenhardt L, Hickman M, Johnson K, Koob GF, et al. Opioid use disorder. Nat Rev Dis Primers. 2020;6(1):3. doi: 10.1038/s41572-019-0137-5.

3. Harned M, Sloan P. Safety concerns with long-term opioid use. Expert Opin Drug Saf. 2016;15(7):955-62. doi: 10.1080/14740338.2016.1177509.

4. Kosten TR, Baxter LE. Review article: Effective management of opioid withdrawal symptoms: A gateway to opioid dependence treatment. Am J Addict. 2019;28(2):55-62. doi: 10.1111/ajad.12862.

5. Murnion B. Management of opioid substitution therapy during medical intervention. Intern Med J. 2012;42(3):242-6. doi: 10.1111/j.1445-5994.2012.02714.X.

6. Hurd YL, Yoon M, Manini AF, Hernandez S, Olmedo R, Ostman $M$, et al. Early Phase in the Development of Cannabidiol as a Treatment for Addiction: Opioid Relapse Takes Ini- 
tial Center Stage. Neurotherapeutics. 2015;12(4):807-15. doi: 10.1007/s13311-015-0373-7.

7. Henry-Edwards S, Gowing L, White J, Ali R, Bell J, Brough $\mathrm{R}$, et al. Clinical Guidelines and Procedures for the Use of Methadone in the Maintenance Treatment of Opioid Dependence. Canberra, Australia: Australian Government Department of Health and Ageing; 2003. OCLC: 224028040.

8. Lintzaris N, Clark N, Winstock A, Dunlop A, Muhleisen P, Gowing $\mathrm{L}$, et al. National clinical guidelines and procedures for the use of buprenorphine in the treatment of opioid dependence. Canberra, Australia: Australian Government Department of Health and Ageing; 2006. OCLC: 225345629.

9. Kaufling J, Aston-Jones G. Persistent Adaptations in Afferents to Ventral Tegmental Dopamine Neurons after Opiate Withdrawal. J Neurosci. 2015;35(28):10290-303. doi: 10.1523/JNEUROSCI.0715-15.2015.

10. Welsch L, Bailly J, Darcq E, Kieffer BL. The Negative Affect of Protracted Opioid Abstinence: Progress and Perspectives From Rodent Models. Biol Psychiatry. 2020;87(1):54-63. doi: 10.1016/j.biopsych.2019.07.027.

11. Bergeria CL, Huhn AS, Dunn KE. The impact of naturalistic cannabis use on self-reported opioid withdrawal. J Subst Abuse Treat. 2020;113:108005. doi: 10.1016/j.jsat.2020.108005.

12. Kral AH, Wenger L, Novak SP, Chu D, Corsi KF, Coffa D, et al. Is cannabis use associated with less opioid use among people who inject drugs? Drug Alcohol Depend. 2015;153:236-41. doi: 10.1016/j.drugalcdep.2015.05.014.

13. Kim JH, Santaella-Tenorio J, Mauro C, Wrobel J, Cerda $\mathrm{M}$, Keyes KM, et al. State Medical Marijuana Laws and the Prevalence of Opioids Detected Among Fatally Injured Drivers. Am J Public Health. 2016;106(11):2032-2037. doi: 10.2105/AJPH.2016.303426.

14. Scavone JL, Sterling RC, Van Bockstaele EJ. Cannabinoid and opioid interactions: implications for opiate dependence and withdrawal. Neuroscience. 2013;248:637-54. doi: 10.1016/j.neuroscience.2013.04.034.

15. Fattore L, Deiana S, Spano SM, Cossu G, Fadda P, Scherma $M$, et al. Endocannabinoid system and opioid addiction: behavioural aspects. Pharmacol Biochem Behav. 2005;81(2):343-59. doi: 10.1016/j.pbb.2005.01.031.

16. Robledo P, Berrendero F, Ozaita A, Maldonado R. Advances in the field of cannabinoid-opioid cross-talk. Addict Biol. 2008;13(2):213-24. doi: 10.1111/j.1369-1600.2008.00107.x.

17. Mansour A, Fox CA, Akil H, Watson SJ. Opioid-receptor mRNA expression in the rat CNS: anatomical and functional implications. Trends Neurosci. 1995;18(1):22-9. doi: 10.1016/0166-2236(95)93946-u.

18. Kieffer BL, Gaveriaux-Ruff C. Exploring the opioid system by gene knockout. Prog Neurobiol. 2002;66(5):285-306. doi: 10.1016/s0301-0082(02)00008-4.

19. Rodriguez JJ, Mackie K, Pickel VM. Ultrastructural localization of the CB1 cannabinoid receptor in mu-opioid receptor patches of the rat Caudate putamen nucleus. J Neurosci. 2001;21(3):823-33. doi: 10.1523/JNEUROSCI.21-0300823.2001.

20. Law PY, Wong YH, Loh HH. Molecular mechanisms and regulation of opioid receptor signaling. Annu Rev Pharmacol Toxicol. 2000;40:389-430. doi: 10.1146/annurev.pharmtox.40.1.389.

21. Charbogne P, Kieffer BL, Befort K. 15 years of genetic approaches in vivo for addiction research: Opioid receptor and peptide gene knockout in mouse models of drug abuse. Neuropharmacology. 2014;76 Pt B:204-17. doi: 10.1016/j.neuropharm.2013.08.028.

22. Bailey CP, Husbands SM. Novel approaches for the treatment of psychostimulant and opioid abuse - focus on opioid receptor-based therapies. Expert Opin Drug Discov.
2014;9(11):1333-44. doi: 10.1517/17460441.2014.964203.

23. Bhargava HN. Multiple opiate receptors of brain and spinal cord in opiate addiction. Gen Pharmacol. 1991;22(5):767-72. doi: 10.1016/0306-3623(91)90202-h.

24. Chartoff EH, Connery HS. It's MORe exciting than mu: crosstalk between mu opioid receptors and glutamatergic transmission in the mesolimbic dopamine system. Front Pharmacol. 2014;5:116. doi: 10.3389/fphar.2014.00116.

25. Kalivas PW. The glutamate homeostasis hypothesis of addiction. Nat Rev Neurosci. 2009;10(8):561-72. doi: 10.1038/nrn2515.

26. Bisogno T, Ligresti A, Di Marzo V. The endocannabinoid signalling system: biochemical aspects. Pharmacol Biochem Behav. 2005;81(2):224-38. doi: 10.1016/j.pbb.2005.01.027.

27. Keimpema E, Mackie K, Harkany T. Molecular model of cannabis sensitivity in developing neuronal circuits. Trends Pharmacol Sci. 2011;32(9):551-61. doi: 10.1016/j.tips.2011.05.004.

28. Chen DJ, Gao M, Gao FF, Su QX, Wu J. Brain cannabinoid receptor 2: expression, function and modulation. Acta Pharmacol Sin. 2017;38(3):312-316. doi: 10.1038/aps.2016.149.

29. Mallipeddi S, Janero DR, Zvonok N, Makriyannis A. Functional selectivity at G-protein coupled receptors: Advancing cannabinoid receptors as drug targets. Biochem Pharmacol. 2017;128:1-11. doi: 10.1016/j.bcp.2016.11.014.

30. Mailleux P, Vanderhaeghen JJ. Distribution of neuronal cannabinoid receptor in the adult rat brain: a comparative receptor binding radioautography and in situ hybridization histochemistry. Neuroscience. 1992;48(3):655-68. doi: 10.1016/0306-4522(92)90409-u.

31. Herkenham M, Lynn AB, Little MD, Johnson MR, Melvin LS, de Costa BR, et al. Cannabinoid receptor localization in brain. Proc Natl Acad Sci U S A. 1990;87(5):1932-6. PMID: 2308954.

32. Chye Y, Christensen E, Solowij N, Yucel M. The Endocannabinoid System and Cannabidiol's Promise for the Treatment of Substance Use Disorder. Front Psychiatry. 2019;10:63. doi: 10.3389/fpsyt.2019.00063.

33. Pugh J G, Mason J D J, Combs V, Welch SP. Involvement of dynorphin $\mathrm{B}$ in the antinociceptive effects of the cannabinoid CP55,940 in the spinal cord. J Pharmacol Exp Ther. 1997;281(2):730-7. PMID: 9152379.

34. Pugh J G, Smith PB, Dombrowski DS, Welch SP. The role of endogenous opioids in enhancing the antinociception produced by the combination of delta 9-tetrahydrocannabinol and morphine in the spinal cord. J Pharmacol Exp Ther. 1996;279(2):608-16. PMID: 8930163.

35. Shapira M, Gafni $M$, Sarne Y. Long-term interactions between opioid and cannabinoid agonists at the cellular level: cross-desensitization and downregulation. Brain Res. 2003;960(1-2):190-200. doi: 10.1016/s00o68993(02)03842-8.

36. Welch SP, Eads M. Synergistic interactions of endogenous opioids and cannabinoid systems. Brain Res. 1999;848(12):183-90. doi: 10.1016/s0006-8993(99)01908-3.

37. Kathmann M, Flau K, Redmer A, Trankle C, Schlicker E. Cannabidiol is an allosteric modulator at mu- and deltaopioid receptors. Naunyn Schmiedebergs Arch Pharmacol. 2006;372(5):354-61. doi: 10.1007/s00210-006-0033-x.

38. Haller VL, Stevens DL, Welch SP. Modulation of opioids via protection of anandamide degradation by fatty acid amide hydrolase. Eur J Pharmacol. 2008;600(1-3):50-8. doi: 10.1016/j.ejphar.2008.08.005.

39. Navarro M, Carrera MR, Fratta W, Valverde O, Cossu G, Fattore L, et al. Functional interaction between opioid and cannabinoid receptors in drug self-administration. J Neurosci. 2001;21(14):5344-50. doi: 10.1523/JNEUROSCI.21-1405344.2001.

40. Gonzalez S, Schmid PC, Fernandez-Ruiz J, Krebsbach R, 
Schmid HH, Ramos JA. Region-dependent changes in endocannabinoid transmission in the brain of morphinedependent rats. Addict Biol. 2003;8(2):159-66. doi: 10.1080/1355621031000117383.

41. Ghozland S, Matthes HW, Simonin F, Filliol D, Kieffer BL, Maldonado R. Motivational effects of cannabinoids are mediated by mu-opioid and kappa-opioid receptors. J Neurosci. 2002;22(3):1146-54. doi: 10.1523/JNEUROSCI.22-0301146.2002.

42. Castane A, Robledo P, Matifas A, Kieffer BL, Maldonado R. Cannabinoid withdrawal syndrome is reduced in double $\mathrm{mu}$ and delta opioid receptor knockout mice. Eur J Neurosci. 2003;17(1):155-9. doi: 10.1046/j.1460-9568.2003.02409.x.

43. Hoffman AF, Lupica CR. Synaptic targets of $\Delta^{9}$ tetrahydrocannabinol in the central nervous system. Cold Spring Harb Perspect Med. 2013;3(8). doi: 10.1101/cshperspect.a012237.

44. Hine B, Friedman E, Torrelio M, Gershon S. Morphinedependent rats: blockade of precipitated abstinence by tetrahydrocannabinol. Science. 1975;187(4175):443-5. doi: 10.1126/science.1167428.

45. Bhargava HN. Effect of some cannabinoids on naloxoneprecipitated abstinence in morphine-dependent mice. Psychopharmacology (Berl). 1976;49(3):267-70. doi: 10.1007/BF00426828.

46. Gamage TF, Ignatowska-Jankowska BM, Muldoon PP, Cravatt $B F$, Damaj MI, Lichtman AH. Differential effects of endocannabinoid catabolic inhibitors on morphine withdrawal in mice. Drug Alcohol Depend. 2015;146:7-16. doi: 10.1016/j.drugalcdep.2014.11.015.

47. Bhargava HN. Time course of the effects of naturally occurring cannabinoids on morphine abstinence syndrome. Pharmacol Biochem Behav. 1978;8(1):7-11. doi: 10.1016/00913057(78)90115-6.

48. Bhargava HN. Inhibition of naloxone-induced withdrawal in morphine dependent mice by 1 -trans $-\Delta^{9}$ tetrahydrocannabinol. Eur J Pharmacol. 1976;36(1):259-62. doi: 10.1016/0014-2999(76)90283-1.

49. Yamaguchi T, Hagiwara $\mathrm{Y}$, Tanaka $\mathrm{H}$, Sugiura T, Waku $\mathrm{K}$, Shoyama Y, et al. Endogenous cannabinoid, 2arachidonoylglycerol, attenuates naloxone-precipitated withdrawal signs in morphine-dependent mice. Brain Res. 2001;909(1-2):121-6. doi: 10.1016/s0006-8993(01)02655-5.

50. Bisaga A, Sullivan MA, Glass A, Mishlen K, Pavlicova M, Haney $M$, et al. The effects of dronabinol during detoxification and the initiation of treatment with extended release naltrexone. Drug Alcohol Depend. 2015;154:38-45. doi: 10.1016/j.drugalcdep.2015.05.013.

51. Lofwall MR, Babalonis S, Nuzzo PA, Elayi SC, Walsh SL. Opioid withdrawal suppression efficacy of oral dronabinol in opioid dependent humans. Drug Alcohol Depend. 2016;164:143150. doi: 10.1016/j.drugalcdep.2016.05.002.

52. Jicha CJ, Lofwall MR, Nuzzo PA, Babalonis S, Elayi SC, Walsh SL. Safety of oral dronabinol during opioid withdrawal in humans. Drug Alcohol Depend. 2015;157:179-83. doi: 10.1016/j.drugalcdep.2015.09.031.

53. White NM. Reward or reinforcement: what's the difference? Neurosci Biobehav Rev. 1989;13(2-3):181-6. doi: 10.1016/s0149-7634(89)80028-4.

54. Li JX, Koek W, France CP. Interactions between $\Delta^{9}$ tetrahydrocannabinol and heroin: self-administration in rhesus monkeys. Behav Pharmacol. 2012;23(8):754-61. doi: 10.1097/FBP.ob013e32835a3907.

55. Maguire DR, France CP. Effects of daily delta9-tetrahydrocannabinol treatment on heroin selfadministration in rhesus monkeys. Behav Pharmacol. 2016;27(2-3 Spec Issue):249-57. doi: 10.1097/FBP.0000000000000192.
56. Solinas M, Goldberg SR. Motivational effects of cannabinoids and opioids on food reinforcement depend on simultaneous activation of cannabinoid and opioid systems. Neuropsychopharmacology. 2005;30(11):2035-45. doi: 10.1038/sj.npp.1300720.

57. Hudson R, Renard J, Norris C, Rushlow WJ, Laviolette SR. Cannabidiol Counteracts the Psychotropic SideEffects of $\Delta-9$-Tetrahydrocannabinol in the Ventral Hippocampus through Bidirectional Control of ERK1-2 Phosphorylation. J Neurosci. 2019;39(44):8762-8777. doi: 10.1523/JNEUROSCI.0708-19.2019.

58. Fattore L, Spano MS, Cossu G, Deiana S, Fratta W. Cannabinoid mechanism in reinstatement of heroin-seeking after a long period of abstinence in rats. Eur J Neurosci. 2003;17(8):1723-6. doi: 10.1046/j.1460-9568.2003.02607.x.

59. Schneider M. Puberty as a highly vulnerable developmental period for the consequences of cannabis exposure. Addict Biol. 2008;13(2):253-63. doi: 10.1111/j.13691600.2008.00110.x.

60. Ellgren M, Spano SM, Hurd YL. Adolescent cannabis exposure alters opiate intake and opioid limbic neuronal populations in adult rats. Neuropsychopharmacology. 2007;32(3):607-15. doi: 10.1038/sj.npp.1301127.

61. Solinas M, Panlilio LV, Goldberg SR. Exposure to $\Delta^{-}$ 9-tetrahydrocannabinol (THC) increases subsequent heroin taking but not heroin's reinforcing efficacy: a selfadministration study in rats. Neuropsychopharmacology. 2004;29(7):1301-11. doi: 10.1038/sj.npp.1300431.

62. Stopponi S, Soverchia L, Ubaldi M, Cippitelli A, Serpelloni G, Ciccocioppo R. Chronic THC during adolescence increases the vulnerability to stress-induced relapse to heroin seeking in adult rats. Eur Neuropsychopharmacol. 2014;24(7):1037-45. doi: 10.1016/j.euroneuro.2013.12.012.

63. Cadoni C. Fischer 344 and Lewis Rat Strains as a Model of Genetic Vulnerability to Drug Addiction. Front Neurosci. 2016;10:13. doi: 10.3389/fnins.2016.00013.

64. Cadoni C, Simola N, Espa E, Fenu S, Di Chiara G. Strain dependence of adolescent Cannabis influence on heroin reward and mesolimbic dopamine transmission in adult Lewis and Fischer 344 rats. Addict Biol. 2015;20(1):132-42. doi: 10.1111/adb.12085.

65. Lecca D, Scifo A, Pisanu A, Valentini V, Piras G, Sil A, et al. Adolescent cannabis exposure increases heroin reinforcement in rats genetically vulnerable to addiction. Neuropharmacology. 2020;166:107974. doi: 10.1016/j.neuropharm.2020.107974.

66. Nguyen JD, Creehan KM, Kerr TM, Taffe MA. Lasting effects of repeated $\Delta^{9}$-tetrahydrocannabinol vapour inhalation during adolescence in male and female rats. $\mathrm{Br} \mathrm{J}$ Pharmacol. 2020;177(1):188-203. doi: 10.1111/bph.14856.

67. Nguyen JD, Grant Y, Creehan KM, Hwang CS, Vandewater SA, Janda KD, et al. $\Delta^{9}$-tetrahydrocannabinol attenuates oxycodone self-administration under extended access conditions. Neuropharmacology. 2019;151:127-135. doi: 10.1016/j.neuropharm.2019.04.010.

68. Romanelli L, Palmery M, Tucci P, Amico MC, Morrone $\mathrm{LA}$, Valeri P. Involvement of the cannabinoid CB1 receptor in the opioid inhibition of the response to cholecystokinin and acute withdrawal response. Neurotoxicology. 2005;26(5):819-27. doi: 10.1016/j.neuro.2005.03.010.

69. Manzanedo C, Aguilar MA, Rodriguez-Arias M, Navarro M, Minarro J. Cannabinoid agonistinduced sensitisation to morphine place preference in mice. Neuroreport. 2004;15(8):1373-7. doi: 10.1097/01.wnr.0000126217.87116.8c.

70. Haghparast A, Shamsizadeh A, Samandari R, Omranifard A, Vaziri A, Razavi Y. Cannabinoid receptors in the basolateral amygdala are involved in the potentiation of mor- 
phine rewarding properties in the acquisition, but not expression of conditioned place preference in rats. Brain Res. 2014;1565:28-36. doi: 10.1016/j.brainres.2014.04.003.

71. Norwood CS, Cornish JL, Mallet PE, McGregor IS. Preexposure to the cannabinoid receptor agonist CP 55940 enhances morphine behavioral sensitization and alters morphine self-administration in Lewis rats. Eur J Pharmacol. 2003;465(1-2):105-14. doi: 10.1016/s0014-2999(03)014559 .

72. Solinas M, Panlilio LV, Tanda G, Makriyannis A, Matthews SA, Goldberg SR. Cannabinoid agonists but not inhibitors of endogenous cannabinoid transport or metabolism enhance the reinforcing efficacy of heroin in rats. Neuropsychopharmacology. 2005;30(11):2046-57. doi: 10.1038/sj.npp.1300754.

73. Maguire DR, Yang W, France CP. Interactions between $\mu$-opioid receptor agonists and cannabinoid receptor agonists in rhesus monkeys: antinociception, drug discrimination, and drug self-administration. J Pharmacol Exp Ther. 2013;345(3):354-62. doi: 10.1124/jpet.113.204099.

74. Braida D, Pozzi M, Parolaro D, Sala M. Intracerebral self-administration of the cannabinoid receptor agonist CP 55,940 in the rat: interaction with the opioid system. Eur J Pharmacol. 2001;413(2-3):227-34. doi: 10.1016/s00142999(01)00766-x.

75. Braida D, Pozzi M, Cavallini R, Sala M. Conditioned place preference induced by the cannabinoid agonist $\mathrm{CP}$ 55,940: interaction with the opioid system. Neuroscience. 2001;104(4):923-6. doi: 10.1016/s0306-4522(01)00210-x.

76. Ahmad T, Sun N, Lyons D, Laviolette SR. Bi-directional cannabinoid signalling in the basolateral amygdala controls rewarding and aversive emotional processing via functional regulation of the nucleus accumbens. Addict Biol. 2017;22(5):1218-1231. doi: 10.1111/adb.12406.

77. De Vries TJ, Homberg JR, Binnekade R, Raaso H, Schoffelmeer ANM. Cannabinoid modulation of the reinforcing and motivational properties of heroin and heroin-associated cues in rats. Psychopharmacology (Berl). 2003;168(12):164-169. doi: 10.1007/s00213-003-1422-1.

78. Khaleghzadeh-Ahangar $\mathrm{H}$, Haghparast $\mathrm{A}$. Intra-accumbal Cannabinoid Agonist Attenuated Reinstatement but not Extinction Period of Morphine-Induced Conditioned Place Preference; Evidence for Different Characteristics of Extinction Period and Reinstatement. Neurochem Res. 2017;42(11):3321-3330. doi: 10.1007/s11064-017-2374-x.

79. Khaleghzadeh-Ahangar H, Khodagholi F, Shaerzadeh F, Haghparast A. Modulatory role of the intra-accumbal CB1 receptor in protein level of the $\mathrm{c}-$ fos and PCREB/CREB ratio in the nucleus accumbens and ventral tegmental area in extinction and morphine seeking in the rats. Brain Res Bull. 2018;142:320-327. doi: 10.1016/j.brainresbull.2018.08.017.

80. Khaleghzadeh-Ahangar H, Haghparast A. Cannabinoid receptor modulation changes the accumbal neuronal responses to morphine in the reinstatement of morphine-induced conditioned place preference. Addict Biol. 2019; p. e12817. doi: 10.1111/adb.12817.

81. O'Neal TJ, Nooney MN, Thien K, Ferguson SM. Chemogenetic modulation of accumbens direct or indirect pathways bidirectionally alters reinstatement of heroin-seeking in high- but not low-risk rats. Neuropsychopharmacology. 2020;45(8):1251-1262. doi: 10.1038/s41386-019-0571-9.

82. Bossert JM, Adhikary S, St Laurent R, Marchant NJ, Wang HL, Morales M, et al. Role of projections from ventral subiculum to nucleus accumbens shell in context-induced reinstatement of heroin seeking in rats. Psychopharmacology (Berl). 2016;233(10):1991-2004. doi: 10.1007/s00213-015-4060-5.

83. Hearing MC, Jedynak J, Ebner SR, Ingebretson A, Asp AJ, Fischer RA, et al. Reversal of morphine-induced cell- type-specific synaptic plasticity in the nucleus accumbens shell blocks reinstatement. Proc Natl Acad Sci U S A. 2016;113(3):757-62. doi: 10.1073/pnas.1519248113.

84. Pertwee RG. The diverse CB1 and CB2 receptor pharmacology of three plant cannabinoids: delta9-tetrahydrocannabinol, cannabidiol and $\Delta^{9}$-tetrahydrocannabivarin. Br J Pharmacol. 2008;153(2):199-215. doi: 10.1038/sj.bjp.0707442.

85. Galaj E, Xi ZX. Possible Receptor Mechanisms Underlying Cannabidiol Effects on Addictive-like Behaviors in Experimental Animals. Int J Mol Sci. 2020;22(1). doi: 10.3390/ijms22010134.

86. Campos AC, Ferreira FR, Guimaraes FS. Cannabidiol blocks long-lasting behavioral consequences of predator threat stress: possible involvement of 5HT1A receptors. J Psychiatr Res. 2012;46(11):1501-10. doi: 10.1016/j.jpsychires.2012.08.012.

87. Russo EB, Burnett A, Hall B, Parker KK. Agonistic properties of cannabidiol at 5-HT1a receptors. Neurochem Res. 2005;30(8):1037-43. doi: 10.1007/s11064-005-6978-1.

88. Laprairie RB, Bagher AM, Kelly ME, Denovan-Wright EM. Cannabidiol is a negative allosteric modulator of the cannabinoid CB1 receptor. Br J Pharmacol. 2015;172(20):4790-805. doi: 10.1111/bph.13250.

89. Bisogno T, Hanus L, De Petrocellis L, Tchilibon S, Ponde DE, Brandi I, et al. Molecular targets for cannabidiol and its synthetic analogues: effect on vanilloid VR1 receptors and on the cellular uptake and enzymatic hydrolysis of anandamide. Br J Pharmacol. 2001;134(4):845-52. doi: 10.1038/sj.bjp.0704327.

90. Hine B, Torrelio M, Gershon S. Differential effect of cannabinol and cannabidiol on THC-induced responses during abstinence in morphine-dependent rats. Res Commun Chem Pathol Pharmacol. 1975;12(1):185-8. PMID: 1237925.

91. Katsidoni V, Anagnostou I, Panagis G. Cannabidiol inhibits the reward-facilitating effect of morphine: involvement of 5-HT1A receptors in the dorsal raphe nucleus. Addict Biol. 2013;18(2):286-96. doi: 10.1111/j.1369-1600.2012.00483.x.

92. Ren Y, Whittard J, Higuera-Matas A, Morris CV, Hurd YL. Cannabidiol, a nonpsychotropic component of cannabis, inhibits cue-induced heroin seeking and normalizes discrete mesolimbic neuronal disturbances. J Neurosci. 2009;29(47):14764-9. doi: 10.1523/JNEUROSCI.429109.2009 .

93. de Carvalho CR, Takahashi RN. Cannabidiol disrupts the reconsolidation of contextual drug-associated memories in Wistar rats. Addict Biol. 2017;22(3):742-751. doi: 10.1111/adb.12366.

94. Hurd YL, Spriggs S, Alishayev J, Winkel G, Gurgov K, Kudrich C, et al. Cannabidiol for the Reduction of Cue-Induced Craving and Anxiety in Drug-Abstinent Individuals With Heroin Use Disorder: A Double-Blind Randomized PlaceboControlled Trial. Am J Psychiatry. 2019;176(11):911-922. doi: 10.1176/appi.ajp.2019.18101191.

95. Capano A, Weaver R, Burkman E. Evaluation of the effects of CBD hemp extract on opioid use and quality of life indicators in chronic pain patients: a prospective cohort study. Postgrad Med. 2020;132(1):56-61. doi: 10.1080/00325481.2019.1685298.

96. Galaj E, Xi ZX. Potential of Cannabinoid Receptor Ligands as Treatment for Substance Use Disorders. CNS Drugs. 2019;33(10):1001-1030. doi: 10.1007/s40263-019-00664-w.

97. Ramesh D, Ross GR, Schlosburg JE, Owens RA, Abdullah RA, Kinsey SG, et al. Blockade of endocannabinoid hydrolytic enzymes attenuates precipitated opioid withdrawal symptoms in mice. J Pharmacol Exp Ther. 2011;339(1):173-85. doi: 10.1124/jpet.111.181370.

98. Shahidi S, Hasanein P. Behavioral effects of fatty acid amide hydrolase inhibition on morphine withdrawal symptoms. Brain Res Bull. 2011;86(1-2):118-22. doi: 
10.1016/j.brainresbull.2011.06.019.

99. Rock EM, Ayoub SM, Limebeer CL, Gene A, Wills KL, DeVuono MV, et al. Acute naloxone-precipitated morphine withdrawal elicits nausea-like somatic behaviors in rats in a manner suppressed by N-oleoylglycine. Psychopharmacology (Berl). 2020;237(2):375-384. doi: 10.1007/s00213-01905373-2.

100. Ayoub SM, Smoum R, Farag M, Atwal H, Collins SA, Rock EM, et al. Oleoyl alanine (HU595): a stable monomethylated oleoyl glycine interferes with acute naloxone precipitated morphine withdrawal in male rats. Psychopharmacology (Berl). 2020;237(9):2753-2765. doi: 10.1007/s00213020-05570-4.

101. Manwell LA, Satvat E, Lang ST, Allen CP, Leri F, Parker LA. FAAH inhibitor, URB-597, promotes extinction and $\mathrm{CB}_{1}$ antagonist, SR141716, inhibits extinction of conditioned aversion produced by naloxone-precipitated morphine withdrawal, but not extinction of conditioned preference produced by morphine in rats. Pharmacol Biochem Behav. 2009;94(1):154-62. doi: 10.1016/j.pbb.2009.08.002.

102. McCallum AL, Limebeer CL, Parker LA. Reducing endocannabinoid metabolism with the fatty acid amide hydrolase inhibitor, URB597, fails to modify reinstatement of morphine-induced conditioned floor preference and naloxone-precipitated morphine withdrawal-induced conditioned floor avoidance. Pharmacol Biochem Behav. 2010;96(4):496-500. doi: 10.1016/j.pbb.2010.07.010.

103. Petrie GN, Wills KL, Piscitelli F, Smoum R, Limebeer CL, Rock EM, et al. Oleoyl glycine: interference with the aversive effects of acute naloxone-precipitated MWD, but not morphine reward, in male Sprague-Dawley rats. Psychopharmacology (Berl). 2019;236(9):2623-2633. doi: 10.1007/s00213019-05237-9.

104. Wills KL, Vemuri K, Kalmar A, Lee A, Limebeer CL, Makriyannis A, et al. CB1 antagonism: interference with affective properties of acute naloxone-precipitated morphine withdrawal in rats. Psychopharmacology (Berl). 2014;231(22):4291-300. doi: 10.1007/s00213-014-3575-5.

105. Ramesh D, Gamage TF, Vanuytsel T, Owens RA, Abdullah RA, Niphakis MJ, et al. Dual inhibition of endocannabinoid catabolic enzymes produces enhanced antiwithdrawal effects in morphine-dependent mice. Neuropsychopharmacology. 2013;38(6):1039-49. doi: 10.1038/npp.2012.269.

106. Schindler CW, Scherma M, Redhi GH, Vadivel SK, Makriyannis A, Goldberg SR, et al. Self-administration of the anandamide transport inhibitor AM404 by squirrel monkeys. Psychopharmacology (Berl). 2016;233(10):1867-77. doi: 10.1007/s00213-016-4211-3.

107. Gamaleddin I, Guranda M, Scherma M, Fratta W, Makriyannis A, Vadivel SK, et al. $\mathrm{AM}_{4} \mathrm{O} 4$ attenuates reinstatement of nicotine seeking induced by nicotine-associated cues and nicotine priming but does not affect nicotine- and food-taking. J Psychopharmacol. 2013;27(6):564-71. doi: 10.1177/0269881113477710.

108. Vlachou S, Stamatopoulou F, Nomikos GG, Panagis G. Enhancement of endocannabinoid neurotransmission through CB1 cannabinoid receptors counteracts the reinforcing and psychostimulant effects of cocaine. Int J Neuropsychopharmacol. 2008;11(7):905-23. doi: 10.1017/S1461145708008717.

109. Kaur R, Sidhu P, Singh S. What failed BIA 10-2474 Phase I clinical trial? Global speculations and recommendations for future Phase I trials. J Pharmacol Pharmacother. 2016;7(3):120-6. doi: 10.4103/0976-500X.189661.

110. van Esbroeck ACM, Janssen APA, Cognetta r A B, Ogasawara D, Shpak G, van der Kroeg M, et al. Activity-based protein profiling reveals off-target proteins of the FAAH inhibitor BIA 10-2474. Science. 2017;356(6342):1084-1087. doi: $10.1126 /$ science.aaf7497.
111. Gobbi G, Bambico FR, Mangieri R, Bortolato M, Campolongo P, Solinas $\mathrm{M}$, et al. Antidepressant-like activity and modulation of brain monoaminergic transmission by blockade of anandamide hydrolysis. Proc Natl Acad Sci U S A. 2005;102(51):18620-5. doi: 10.1073/pnas.0509591102.

112. Piomelli D, Tarzia G, Duranti A, Tontini A, Mor M, Compton TR, et al. Pharmacological profile of the selective FAAH inhibitor KDS-4103 (URB597). CNS Drug Rev. 2006;12(1):2138. doi: 10.1111/j.1527-3458.2006.00021.x.

113. Justinova Z, Mangieri RA, Bortolato M, Chefer SI, Mukhin AG, Clapper JR, et al. Fatty acid amide hydrolase inhibition heightens anandamide signaling without producing reinforcing effects in primates. Biol Psychiatry. 2008;64(11):930-7. doi: 10.1016/j.biopsych.2008.08.008.

114. Wills KL, Petrie GN, Millett G, Limebeer CL, Rock EM, Niphakis MJ, et al. Double Dissociation of Monoacylglycerol Lipase Inhibition and CB1 Antagonism in the Central Amygdala, Basolateral Amygdala, and the Interoceptive Insular Cortex on the Affective Properties of Acute Naloxone-Precipitated Morphine Withdrawal in Rats. Neuropsychopharmacology. 2016;41(7):1865-73. doi: 10.1038/npp.2015.356.

115. Wilkerson JL, Ghosh S, Mustafa M, Abdullah RA, Niphakis MJ, Cabrera R, et al. The endocannabinoid hydrolysis inhibitor SA-57: Intrinsic antinociceptive effects, augmented morphine-induced antinociception, and attenuated heroin seeking behavior in mice. Neuropharmacology. 2017;114:156-167. doi: 10.1016/j.neuropharm.2016.11.015.

116. Navarro M, Chowen J, Rocio ACM, del Arco I, Villanua MA, Martin Y, et al. CB1 cannabinoid receptor antagonist-induced opiate withdrawal in morphine-dependent rats. Neuroreport. 1998;9(15):3397-402. doi: 10.1097/00001756-19981026000012.

117. Mas-Nieto M, Pommier B, Tzavara ET, Caneparo A, Da Nascimento S, Le Fur G, et al. Reduction of opioid dependence by the $\mathrm{CB}_{1}$ antagonist SR141716A in mice: evaluation of the interest in pharmacotherapy of opioid addiction. Br J Pharmacol. 2001;132(8):1809-16. doi: 10.1038/sj.bjp.0703990.

118. Cossu G, Ledent C, Fattore L, Imperato A, Bohme GA, Parmentier $\mathrm{M}$, et al. Cannabinoid CB1 receptor knockout mice fail to self-administer morphine but not other drugs of abuse. Behav Brain Res. 2001;118(1):61-5. doi: 10.1016/s01664328(00)00311-9.

119. Wills KL, DeVuono MV, Limebeer CL, Vemuri K, Makriyannis A, Parker LA. $\mathrm{CB}_{1}$ receptor antagonism in the bed nucleus of the stria terminalis interferes with affective opioid withdrawal in rats. Behav Neurosci. 2017;131(4):304-11. doi: 10.1037/bneo0o0201.

120. Yuan WX, Heng LJ, Ma J, Wang XQ, Qu LJ, Duan L, et al. Increased expression of cannabinoid receptor 1 in the nucleus accumbens core in a rat model with morphine withdrawal. Brain Res. 2013;1531:102-12. doi: 10.1016/j.brainres.2013.07.047.

121. Alvarez-Jaimes L, Polis I, Parsons LH. Attenuation of cue-induced heroin-seeking behavior by cannabinoid CB1 antagonist infusions into the nucleus accumbens core and prefrontal cortex, but not basolateral amygdala. Neuropsychopharmacology. 2008;33(10):2483-93. doi: 10.1038/sj.npp.1301630.

122. He XH, Jordan CJ, Vemuri K, Bi GH, Zhan J, Gardner EL, et al. Cannabinoid CB1 receptor neutral antagonist AM 4113 inhibits heroin self-administration without depressive side effects in rats. Acta Pharmacol Sin. 2019;40(3):365-373. doi: 10.1038/s41401-018-0059-x.

123. Feja M, Leigh MPK, Baindur AN, McGraw JJ, Wakabayashi KT, Cravatt BF, et al. The novel MAGL inhibitor MJN110 enhances responding to reward-predictive incentive cues by activation of CB1 receptors. Neuropharmacology. 2020;162:107814. doi: 
10.1016/j.neuropharm.2019.107814.

124. Zhang J, Wang N, Chen B, Wang Y, He J, Cai X, et al. Blockade of Cannabinoid CB1 receptor attenuates the acquisition of morphine-induced conditioned place preference along with a downregulation of ERK, CREB phosphorylation, and BDNF expression in the nucleus accumbens and hippocampus. Neurosci Lett. 2016;630:70-76. doi: 10.1016/j.neulet.2016.07.047.

125. Khaleghzadeh-Ahangar $\mathrm{H}$, Haghparast $\mathrm{A}$. Intra-accumbal $\mathrm{CB} 1$ receptor blockade reduced extinction and reinstatement of morphine. Physiol Behav. 2015;149:212-9. doi: 10.1016/j.physbeh.2015.06.005.

126. Zhao $\mathrm{X}$, Yao L, Wang $\mathrm{F}$, Zhang $\mathrm{H}$, Wu L. Cannabinoid 1 receptor blockade in the dorsal hippocampus prevents the reinstatement but not acquisition of morphine-induced conditioned place preference in rats. Neuroreport. 2017;28(10):565-570. doi: 10.1097/WNR.0000000000000796.

127. Pan B, Zhong P, Sun D, Liu QS. Extracellular signalregulated kinase signaling in the ventral tegmental area mediates cocaine-induced synaptic plasticity and rewarding effects. J Neurosci. 2011;31(31):11244-55. doi: 10.1523/JNEUROSCI.1040-11.2011.

128. Lv XF, Sun LL, Cui CL, Han JS. NAc Shell Arc/Arg3.1 Protein Mediates Reconsolidation of Morphine CPP by Increased GluR1 Cell Surface Expression: Activation of ERK-Coupled CREB is Required. Int J Neuropsychopharmacol. 2015;18(9). doi: 10.1093/ijnp/pyv030.

129. Haghparast A, Azizi P, Hassanpour-Ezatti $M$, Khorrami H, Naderi N. Sub-chronic administration of AM251, CB1 receptor antagonist, within the nucleus accumbens induced sensitization to morphine in the rat. Neurosci Lett. 2009;467(1):43-7. doi: 10.1016/j.neulet.2009.09.062.

130. Ahmad T, Lauzon NM, de Jaeger X, Laviolette SR. Cannabinoid transmission in the prelimbic cortex bidirectionally controls opiate reward and aversion signaling through dissociable kappa versus $\mu$-opiate receptor dependent mechanisms. J Neurosci. 2013;33(39):15642-51. doi: 10.1523/JNEUROSCI.1686-13.2013.

131. Iyer V, Slivicki RA, Thomaz AC, Crystal JD, Mackie K, Hohmann AG. The cannabinoid CB2 receptor agonist LY2828360 synergizes with morphine to suppress neuropathic nociception and attenuates morphine reward and physical dependence. Eur J Pharmacol. 2020;886:173544. doi: 10.1016/j.ejphar.2020.173544.

132. Lin $\mathrm{X}$, Dhopeshwarkar AS, Huibregtse $M$, Mackie $K$, Hohmann AG. Slowly signaling $G$ protein-biased $\mathrm{CB}_{2}$ cannabinoid receptor agonist LY2828360 suppresses neuropathic pain with sustained efficacy and attenuates morphine tolerance and dependence. Mol Pharmacol. 2018;93(2):4962. doi: $10.1124 / \mathrm{mol} .117 .109355$

133. Li AL, Lin X, Dhopeshwarkar AS, Thomaz AC, Carey LM, Liu Y, et al. Cannabinoid CB2 Agonist AM1710 Differentially Suppresses Distinct Pathological Pain States and Attenuates Morphine Tolerance and Withdrawal. Mol Pharmacol. 2019;95(2):155-168. doi: 10.1124/mol.118.113233.

134. Zhang M, Dong L, Zou H, Li J, Li Q, Wang G, et al. Effects of Cannabinoid Type 2 Receptor Agonist AM1241 on MorphineInduced Antinociception, Acute and Chronic Tolerance, and Dependence in Mice. J Pain. 2018;19(10):1113-1129. doi: 10.1016/j.jpain.2018.04.009.

135. Grenald SA, Young MA, Wang Y, Ossipov MH, Ibrahim MM, Largent-Milnes TM, et al. Synergistic attenuation of chronic pain using mu opioid and cannabinoid receptor 2 agonists. Neuropharmacology. 2017;116:59-70. doi: 10.1016/j.neuropharm.2016.12.008.

136. Marconi A, Di Forti M, Lewis CM, Murray RM, Vassos E. Metaanalysis of the Association Between the Level of Cannabis Use and Risk of Psychosis. Schizophr Bull. 2016;42(5):1262-9. doi: $10.1093 /$ schbul/sbw003.

137. Navarrete F, Garcia-Gutierrez MS, Manzanares J. Pharmacological regulation of cannabinoid $\mathrm{CB} 2$ receptor modulates the reinforcing and motivational actions of ethanol. Biochem Pharmacol. 2018;157:227-234. doi: 10.1016/j.bcp.2018.07.041.

138. Xi ZX, Peng XQ, Li X, Song R, Zhang HY, Liu QR, et al. Brain cannabinoid $\mathrm{CB}_{2}$ receptors modulate cocaine's actions in mice. Nat Neurosci. 2011;14(9):1160-6. doi: 10.1038/nn.2874.

139. Piazza PV, Deroche-Gamonet V. A multistep general theory of transition to addiction. Psychopharmacology (Berl). 2013;229(3):387-413. doi: 10.1007/s00213-013-3224-4.

\section{Copyright and License}

Copyright (C) 2021. Erin McLemon, Rose Chesworth. Except where otherwise noted, the content of this article is licensed under a Creative Commons Attribution 4.0 International License. You are free to reuse or adapt this article for any purpose, provided appropriate acknowledgement is provided. For additional permissions, please contact the corresponding author. 